\title{
Evaluation of some potential silkworm Bombyx mori L. genotypes during different seasons under temperate conditions
}

\author{
Z. I. Buhroo ${ }^{1}$, M. A. Malik ${ }^{1}$, N. A. Ganai ${ }^{2}$, A. S. Kamili ${ }^{1}$ and S. A. Mir ${ }^{3}$ \\ ${ }^{1}$ Temperate Sericulture Research Institute, Sher-e- Kashmir University of Agricultural Sciences and Technology of \\ Kashmir, Srinagar-190025 (J\&K), INDIA \\ ${ }^{2}$ Division of Animal Breeding and Genetics, Faculty of Veterinary Sciences and Animal Husbandry, \\ Sher-e- Kashmir University of Agricultural Sciences and Technology of Kashmir, Srinagar-190006 (J\&K), INDIA \\ ${ }^{3}$ Division of Statistics, Faculty of Horticultural Sciences, Sher-e- Kashmir University of Agricultural Sciences and \\ Technology of Kashmir, Srinagar-190025 (J\&K), INDIA \\ Corresponding author. E-mail: zafar.buhroo1985@gmail.com \\ Received: October 2, 2016; Revised received: February 19, 2017; Accepted: May 27, 2017
}

\begin{abstract}
In the present study twelve potential bivoltine silkworm Bombyx mori L. genotypes were evaluated for their performance at $25 \pm 1{ }^{\circ} \mathrm{C}$ temperature and $75 \pm 5 \%$ relative humidity for twelve different traits during spring and summer seasons of 2012 and 2013, respectively. The data generated in respect of different traits was pooled separately, analyzed statistically and subjected to multiple trait evaluation indexes. The genotypes were ranked as per the cumulative score and the value of a particular trait in a particular genotype was compared with the ranking. Out of twelve genotypes, six genotypes viz., SKAU-R-1, SKAU-R-6, SKUAST-31, NB ${ }_{4} D_{2}, \mathrm{SH}_{6}$ and SKUAST-28 were shortlisted for spring season and eight genotypes viz., SKAU-R-1, SKAU-R-6, NB $\mathrm{D}_{2}, \mathrm{SH}_{6}, \mathrm{SKUAST}_{-31}, \mathrm{CSR}_{18}$, $D_{U} N_{6}$ and $D_{U N}$ for summer season. These genotypes scored higher $E$ I values $(>50)$ and were identified as promising genotypes hence recommended for rearing under temperate climatic conditions to push up silk productivity in the valley. Furthermore, the genotypes viz., SKAU-R-1, SKAU-R-6, SKUAST-31, NB $\mathrm{D}_{2}, \mathrm{SH}_{6}$, and DUN $\mathrm{N}_{6}$ performed significantly better irrespective of the seasons and scored higher $\mathrm{E}$ I. values $(>50)$. Hence, these genotypes can be recommended for both seasons to boost bivoltine silk production in temperate region.
\end{abstract}

Keywords: Evaluation, Performance, Promising, Silkworm, Seasons, Trait

\section{INTRODUCTION}

Sericulture has an important place in the economy of Jammu and Kashmir as more than 30,000 rural families which belong to economically backward sections of the society are generating their employment through this vocation (Economic Survey, J\&K 2014-15). Being one of the traditional and eco-friendly agro-based labor intensive industries of the state, helps in improving the economic conditions of landless farmers by providing subsidiary employment and supplementing the income of rural farmers especially the economically weaker section of the society (Qadri et al., 2010). The state presents an ideal and fertile land for the growth and development of bivoltine sericulture. Though, the state is known for producing bivoltine silk of international quality. However, production of quality bivoltine silk is still a challenge in J \& $\mathrm{K}$ having enormous potential to produce bivoltine silk of international grade, which can help to reduce the import of bivoltine silk in the country (Malik, 2009). Traditional breeding methods employed during the last few decades has resulted in the development of many productive silkworm breeds which have contributed significantly in maximizing the silk production in India in general and Jammu and Kashmir state in particular. Of late, major thrust has been given for quality rather than quantity of silk produced. Efforts made in this direction during the 90's have lead to the evolution of highly productive CSR bivoltine breeds which have the potential to produce international grade silk (Datta, 2000). However, these new breeds continue to suffer badly in adverse conditions of low/high temperature, humidity, poor leaf quality and low management practices prevalent with the small and marginal farmers in Kashmir. Unlike tropics, temperate sericulture being carried out under highly fluctuating environmental conditions and poor leaf quality urgently needs the development of broad based silkworm breeds with genetic plasticity to buffer the adverse situations.

Evaluation of genetic resources is an essential prerequisite for their effective utilization in order to gauge the extent of variability among genotypes. Silkworms have been evaluated in many environment and agroclimatic conditions in order to identify the season and region specific breeds for utilization (Malik et al., 2002). The necessity for identification of season/region specific breeds/ hybrids arises due to variation in quan- 
titative characters during different environmental conditions. In India, large number of silkworm Bombyx mori $\mathrm{L}$. breeds/hybrids were evolved by various breeders so far suitable for different agro-climatic conditions (Lakashmanan and Suresh kumar,2012; Lakshmi et al., 2012; Gowda et al., 2013; Senapati and Hazarika 2014; Mandal and Moorthy2015 and Gowdaet al., 2016). A series of studies have also been conducted to identify suitable bivoltine silkworm breed for Kashmir valley particularly for spring and autumn seasons (Nisar et al., 2005; Malik et al., 2006; Nisar et al., 2008; Malik et al., 2009, Malik et al., 2010; Malik et al., 2010a and 2010 b). In the present study, an attempt was made to evaluate bivoltine germplasm based on Evaluation index method developed by Mano et al. (1993) which is one such method that increases the precision of selection of breed among an array of breeds by a common index giving due weightage to all the yield component traits (Bhargava et al., 1994). The information generated will be useful to identify most promising genotypes for future breeding of genotypes suitable for temperate regions during spring and summer seasons.

\section{MATERIALS AND METHODS}

Twelve potential bivoltine mulberry silkworm B. mori L. genotypes namely; SKAU-R-1, SKAU-R-6, SKUAST-28, SKUAST-31, CSR $2, \mathrm{CSR}_{4}, \mathrm{CSR}_{18}, \mathrm{CSR}_{19}$, $\mathrm{NB}_{4} \mathrm{D}_{2}, \mathrm{SH}_{6}, \mathrm{DUN}_{6}$ and $\mathrm{DUN}_{22}$ formed basis for this study (Table 1). The disease free laying's (DFL's) of these selected silkworm races were obtained from the Germplasm Bank of Temperate Sericulture Research Institute (TSRI), Sher-e-Kashmir University of Agricultural Sciences and Technology of Kashmir (SKUAST-K) Mirgund, Central Sericultural Germplasm Resources Centre (CSGRC) Hosour, Tamilnadu, India and Central Sericultural Research and Training Institute (CSR\&TI) CSB, Pampore, Srinagar Kashmir. The eggs were incubated under hygienic conditions at $25 \pm 1{ }^{\circ} \mathrm{C}$ temperature and $75-80 \%$ relative humidity for about 10-12 days till their hatching. The silkworms were fed with mulberry leaves harvested from the popular mulberry varieties viz; Goshoerami and Ichinose maintained in Mulberry Germplasm Bank of TSRI, SKUAST-Kashmir, Mirgund. The study was undertaken during the year 2012 and 2013. The spring rearing was conducted in April-May while as summer rearing was conducted during July-August by following the standard package of practices (Krishnaswami, 1978).

The experiment was laid out in Completely Randomized Block Design with three replications for each treatment. Each replication comprised of 250 silkworms of uniform age and size retained after third moult. Rearing was carried out under hygienic conditions. At the end of $5^{\text {th }}$ instar, the mature larvae were collected manually and mounted in plastic collapsible mountages. During the rearing period, larvae and co-

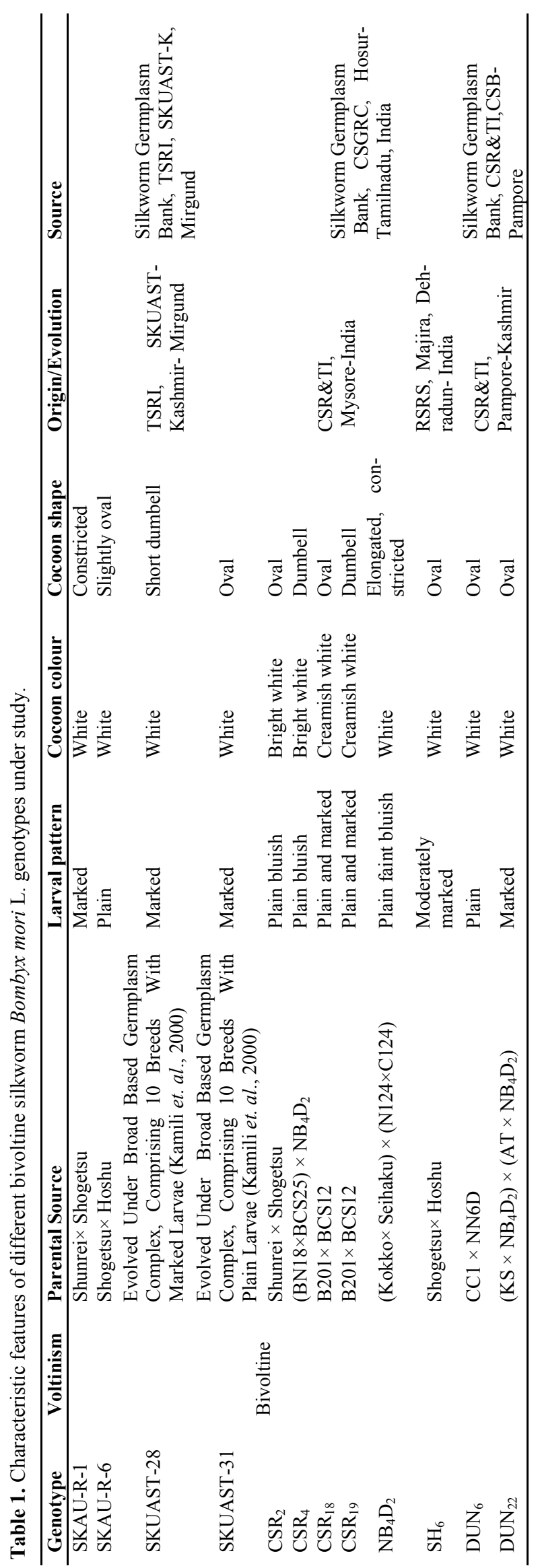



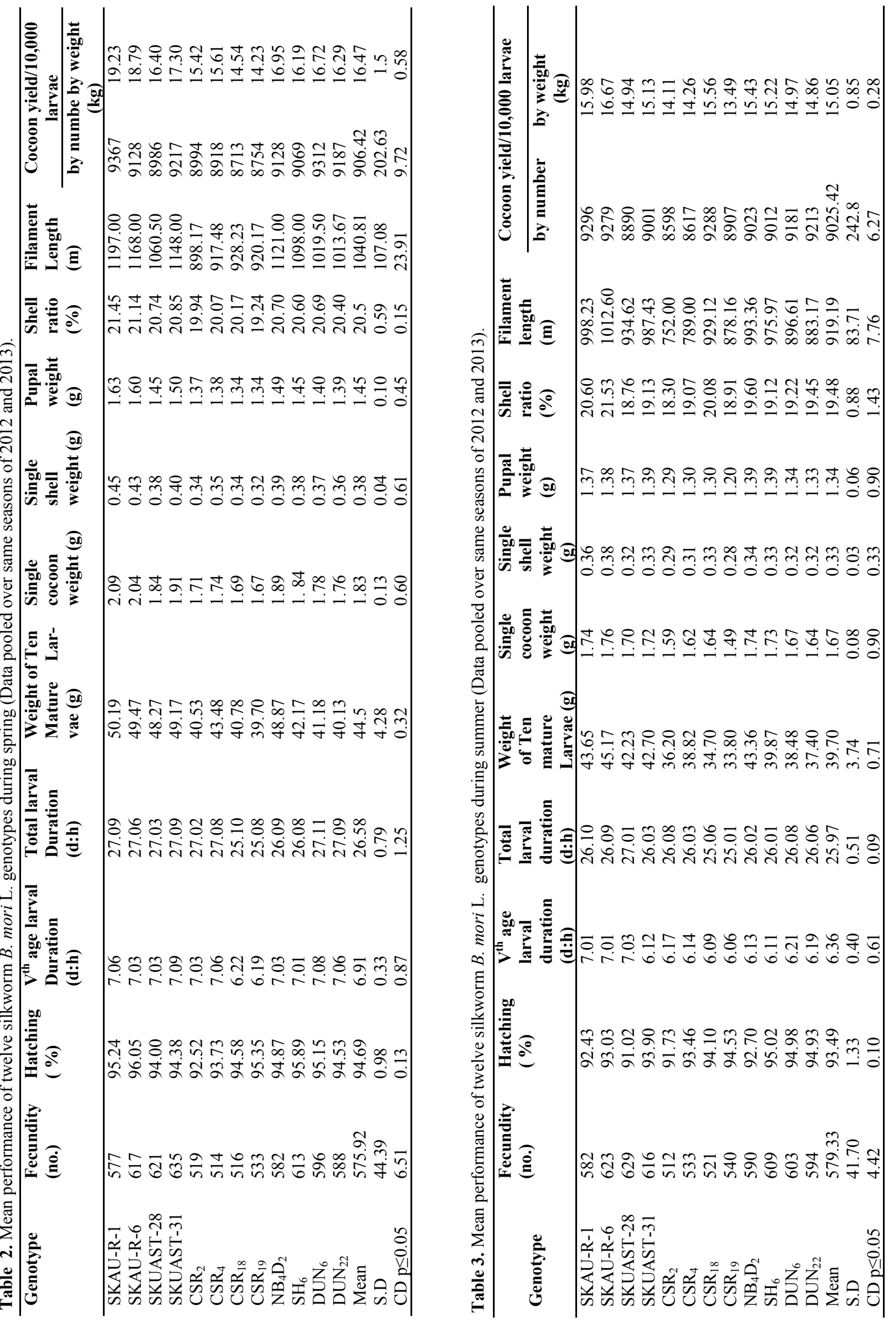
Z. I. Buhroo et al. / J. Appl. \& Nat. Sci. 9 (2): 1264 -1271 (2017)
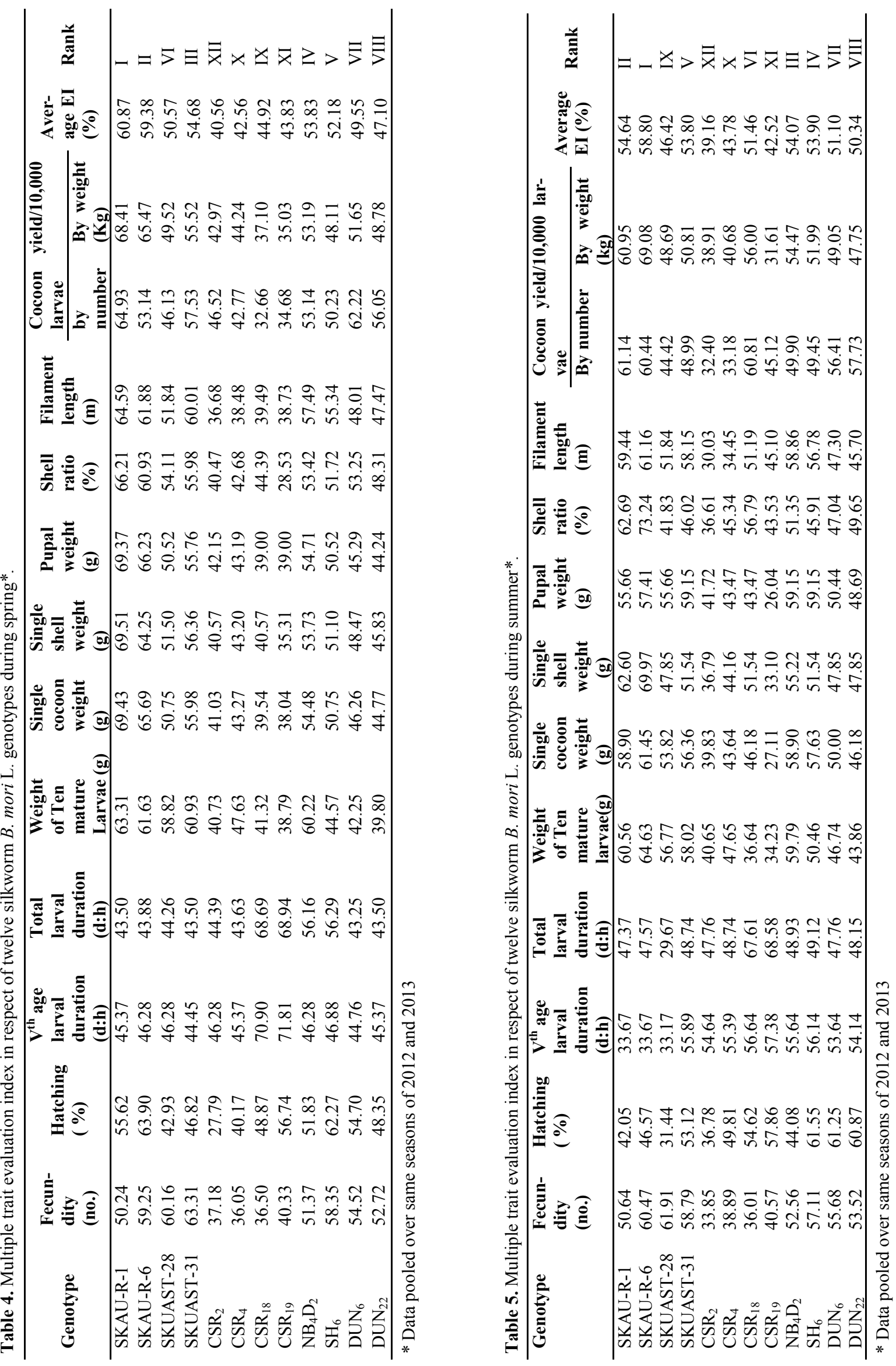


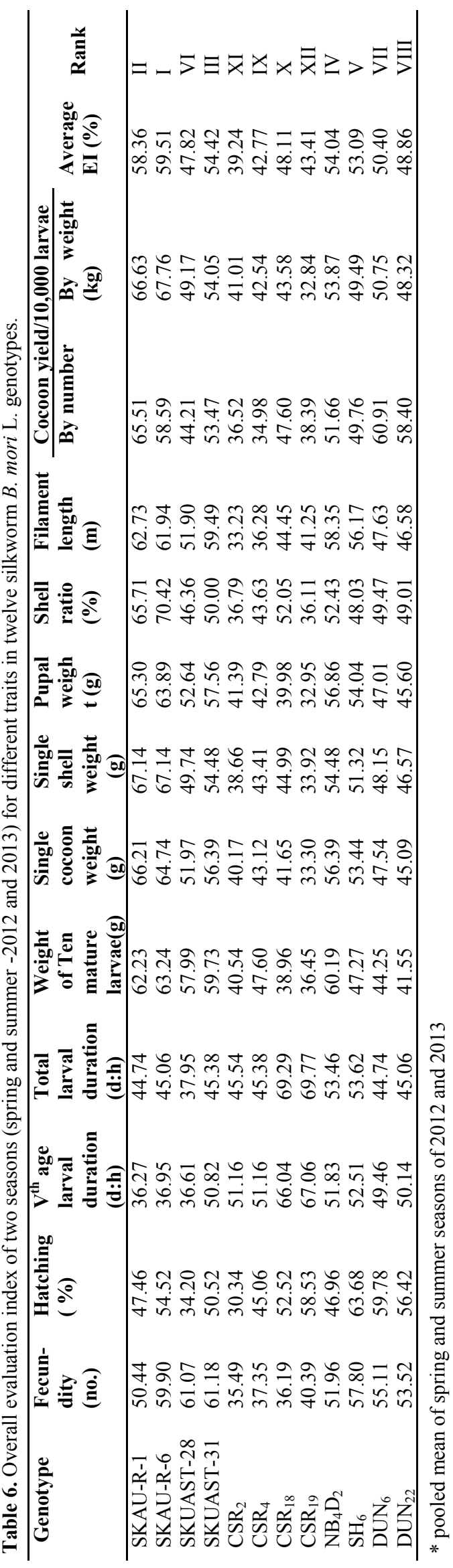

coons were assessed for different parameters viz; fecundity, hatching percentage, larval weight, larval durations (fifth age and total), cocoon yield by weight and by number, single cocoon weight, single shell weight, pupal weight, shell ratio and filament length, during spring and summer seasons (2012 and 2103). The data generated in respect of different traits (Table 2 and 3) was pooled separately, analyzed statistically and subjected further to multiple trait evaluation index method as per the procedure outlined by Mano et al. (1993).

$$
\text { EvaluationIndex }(E I)=\frac{(A-B)}{C} \times 10+50
$$

Where, as evaluation index for $\mathrm{V}^{\text {th }}$ age and total larval durations was computed separately by using the modified formula given by Talebi and Subramanaya (2009).

$$
\text { EvaluationIndex }(E I)=\frac{(B-A)}{C} \times 10+50
$$

Where, $\mathrm{A}=$ Value of a particular breed for particular trait,

$\mathrm{B}=$ Mean value for a particular trait of all the breeds,

$\mathrm{C}=$ Standard Deviation of a particular trait for all the breeds,

$10=$ Standard unit,

$50=$ Fixed value.Minimum/average EI value fixed for selection of a breed is $>50$. The evaluation index value for negative traits viz., $\mathrm{V}^{\text {th }}$ age larval duration and total larval duration was calculated separately. The index value obtained for the entire negative traits was combined and the average EI values were obtained. The EI value fixed for the selection of breed / genotype is 50 or $>50$ for positive traits and 50 or $<50$ for negative traits. The genotypes, which scored above the limit, were considered to possess greater economic value.

\section{RESULTS AND DISCUSSION}

Multiple trait evaluation indices (EI) assessment is the multiple performance of a population for selection/ short-listing of the genotypes/hybrid combinations by taking into consideration all the economic traits. The data recorded from twelve bivoltine silkworm $\mathrm{B}$. mo$r i$ L. genotypes in respect of different traits viz., fecundity, hatching, larval duration, cocoon weight, shell weight, pupal weight, shell ratio, filament length and cocoon yield by number and by weight was subjected to multiple trait evaluation as per the procedure outlined by Mano et al. (1993). Based on the performance of the 12 silkworm genotypes, individual indices were calculated for each of the 12 parameters. Evaluation index values were calculated for each of the genotype in all the 12 parameters for both spring and summer seasons. The data of which is presented in Tables 4-5. The indices obtained from all the traits in respect of each genotype were combined and the average EI values were assessed. The criteria for selection of the genotype was based on the average EI value $>50$. The gen- 
otypes which scored above the limit of 50 in many of the traits were considered to possess greater economic value.

During spring, out of 12 genotypes, 6 genotypes scored the average EI value $>50$. SKAU-R-1 occupied the top position with average EI score value of 60.87 while as in summer, 8 genotypes out of 12 scored average EI value $>50$. SKAU-R-6 recorded the highest average E. I. value of 58.80 among the 12 genotypes evaluated during summer. However, the analysis of data indicates that all the genotypes utilized in the study vary significantly with respect to most of the parameters studied during spring and summer seasons. During spring, $\mathrm{NB}_{4} \mathrm{D}_{2}$ scored E.I values $>50$ for the maximum of 11 traits viz., fecundity, hatching percentage, total larval duration, larval weight, single cocoon weight, single shell weight, pupal weight, shell ratio, filament length, cocoon yield by weight and number. However, this genotype occupied fourth position in the average evaluation index score with an average E.I of 53.83. SKAU-R-1 and SKAU-R-6 scored E.I indices $>50$ for 10 characters. SKUAST-31 and SH6 obtained E.I values $>50$ for 9 characters each (Table-4). While in summer, SKAU-R-1, SKAU-R-6, SKUAST-31, $\mathrm{NB}_{4} \mathrm{D}_{2}$, andSH $\mathrm{H}_{6}$ recorded E.I values $>50$ for the maximum of 9 characters each. Whereas, SKUAST-31, $\mathrm{NB}_{4} \mathrm{D}_{2}$, andSH $\mathrm{H}_{6}$ recorded E.I values $>50$ for other 9 traits followed by $\mathrm{CSR}_{18}, \mathrm{DUN}_{6}$ and $\mathrm{DUN}_{22}$ which obtained E.I values $>50$ for 8,6 and 4 traits respectively (Table-5). Furthermore, evaluation indices obtained irrespective of the seasons revealed that out of 12 genotypes evaluated , 7 genotypes scored average E.I values $>50$. SKAU-R-6 scored average E. I value of 59.51 . Out of 12 characters evaluated, SKUAST-31 and $\mathrm{NB}_{4} \mathrm{D}_{2}$ recorded E.I values $>50$ for the maximum of 11 traits. However, these genotypes occupied third and fourth position in the average evaluation index score with an average E.I of 54.42 and 54.04 respectively. SKAU-R-6 recorded E.I values $>50$ for 10 characters. SKAU-R-1 and $\mathrm{SH}_{6}$ which obtained E.I values $>50$ for 9 and 8 characters respectively (Table-6).

In the recent past evaluation index method developed by Mano et al. (1993) has been utilized for short listing some promising silkworm genotypes/hybrids for commercial exploitation in different seasons under Kashmir climatic conditions (Malik et al., 2009; Malik et al., 2010; Malik et al., 2010a; 2010b; Maqbool et al.,2015 and Nooruldin et al., 2015) and the same has been utilized in the present study as well for evaluating 12 bivoltine silkworm Bombyx mori L. genotypes in respect of different traits viz., fecundity, hatching, larval duration, cocoon weight, shell weight, pupal weight, shell ratio, filament length and cocoon yield by number and by weight. All the top ranking genotypes recorded $>95 \%$ hatching which is well supported by the earlier findings (Nisar et al., 2013). The healthiness of larvae is a very important character from the point of view of silkworm rearers and as such stabilization of cocoon crop is very important for the sericulture industry. The genotypes that have shorter larval duration have less chance to get infected with diseases (Basavaraja et al., 2005). In the present study, out of 12 genotypes two genotypes viz., $\mathrm{CSR}_{18}$ and $\mathrm{CSR}_{19}$ recorded shorter larval duration below 26 days irrespective of seasons (Table 2-3). The single cocoon weight in the top ranking genotypes ranged from 1.84 $\mathrm{g}$ in SKUAST-28 to 2.09 in SKA-U-R-1 during spring (Table-2) while it ranged from $1.64 \mathrm{~g}$ in $\mathrm{DUN}_{22}$ to 1.76 $\mathrm{g}$ in SKA-U-R-6 during summer (Table-3). High cocoon shell weight is an important trait for high productivity. The cocoon shell weight shows variability in different environments. According to Mano et al. (1993), if the breed is showing cocoon shell weight of $0.45 \mathrm{~g}$ and above, it becomes weak and not suitable for summer rearing. The identified genotypes for spring and summer climatic conditions recorded shell weight in the range of $0.38 \mathrm{~g}$ (SKUAST-28) to $0.45 \mathrm{~g}$ (SKA-U $-\mathrm{R}-1)$ in spring while in summer it ranged from $0.32 \mathrm{~g}$ $\left(\mathrm{DUN}_{22}\right)$ to $0.38 \mathrm{~g}$ (SKA-U-R-6). The length of cocoon filament is one of the important attributes of the silkworm breed/hybrid. Longer the filament better, it is to the filature and textile industry. In Japan, almost all the commercial races have been synthesized to satisfy this. The present study identified spring and summer specific genotypes having filament length in the range of $1060 \mathrm{~m}$ to $1197 \mathrm{~m}$ and $883 \mathrm{~m}$ to $1012 \mathrm{~m}$ respectively. Cocoon yield is another very important character connected with the production of cocoons by Sericulturists. It is necessary to have high yielding silkworm genotypes to raise the farmer's income. During spring, the top ranking genotypes recorded cocoon yield/10,000 larvae by number in the range of 8986 to 9367 and yield by weight in the range of $16.40 \mathrm{~kg}$ to $19.23 \mathrm{~kg}$. While in summer it ranged from 9213 to 9279 by number and $14.86 \mathrm{~kg}$ to $16.67 \mathrm{~kg}$ by weight, respectively (Table. 2-3).

In silkworm Bombyx mori L. large numbers of breeds were tested and promising ones were selected based on the economic traits (Lakshmi et al., 2012; Gowda et al., 2013; Mandal et al., 2013; 2015; 2016 and Gowda et al., 2016). Evaluation index is one such method that increases the precision of selection of breed among an array of breeds by a common index giving due weightage to all the yield component traits (Bhargava et al., 1994). The silk yield is contributed by more than 21 traits (Thiagarajan et al., 1993) and there exists an interrelationship between multiple traits in silkworm. Any effort to improve the yield requires consideration of cumulative effect of the major traits, which influences the silk yield impartially. To judge the superiority of the silkworm breeds, a common index method is required (Bhargava et. al., 1994, Mano et. al. 1993). A selection index makes it possible to select for a charac- 
ter by selecting simultaneously for two or more characters related to it. Obviously, the present investigation on performance of some potential bivoltine silkworm genotypes with reference to important economic traits has yielded rich information, to identify promising breeds which can be recommended for commercial exploitation in the interest of the temperate bivoltine silk industry for pushing up the quality silk production.

\section{Conclusion}

Based on the performance and evaluation indices of 12 silkworm B. mori L. genotypes during spring and summer seasons, six genotypes viz., SKAU-R-1, SKAU-R6, SKUAST-31, $\mathrm{NB}_{4} \mathrm{D}_{2}, \mathrm{SH}_{6}$ and SKUAST-28were shortlisted for spring season and eight genotypes viz., SKAU-R-1, SKAU-R-6, NB $\mathrm{D}_{2}, \mathrm{SH}_{6}$, SKUAST-31, $\mathrm{CSR}_{18}, \mathrm{DUN}_{6}$ and $\mathrm{DUN}_{22}$ for summer season. These genotypes scored higher E I. values $(>50)$ and have been identified as promising genotypes hence recommended for rearing under spring and summer climatic conditions of temperate region to push up silk productivity in the valley. Based on the overall performance of genotypes during both seasons (spring and summer) SKAU-R-1, SKAU-R-6, SKUAST-31, NB $\mathrm{D}_{2}, \mathrm{SH}_{6}$, and $\mathrm{DUN}_{6}$ performed significantly better irrespective of the season and scored higher E I. values $(>50)$. Hence, these genotypes can be reared in both seasons to boost bivoltine silk production in the temperate region.

\section{ACKNOWLEGEMENTS}

The first author wishes to thank Directorate of Research, Sher-e- Kashmir University of Agricultural Sciences and Technology of Kashmir, Srinagar-India for financial support. The author sincerely acknowledges Director, CSGRC Hosur, Director, CSR and TI Pampore (Central Silk Board, Ministry of Science and Technology, Govt. of India) and Head, TSRI, SKUAST-K, Mirgund for proving silkworm germplasm laboratory facilities to conduct silk worm rearing.

\section{REFERENCES}

Basavaraja, H. K., Ashwath, S. K., Suresh Kumar, N., Mal Reddy, N. and Kalpana, G. V. (2005). Breeding for disease resistance. In: Silkworm Breeding \& Genetics.Central Silk Board,(Ministry of Textiles) Govt. of India Bangalore India, Pp. 523

Bhargava, S. K., Raja Lakshmi, E. and Thiagarajan, V. (1994). An evaluation index for silk yield contributing traits in Bombyx mori L. Indian Textile Journal, 105:83 - 84

Bhargava, S. K., Thiagarajan, V and Majumdar, M. K. (1993). Impact of silkworm breeds on reeling parameters. Indian Textile Journal, 104: 66 - 69

Datta, R. K. (2000). Silkworm breeding in India; present status and new challenges. In: National conference on strategies for sericulture research and development. November 16-18, 2000. CSR and TI, CSB (Ministry of Textiles) Govt. of India, Srirampura, Mysore-India.
Economic Survey, J\&K (2013-14). Sericulture in Jammu and Kashmir. In: Directorate of Economics and Statistics, Govt., of Jammu and Kashmir, Srinagar, Pp. 37-138

Gowda, V., Balachandran, N and Mishra, P. K. (2016). Studies on the performance of multivoltine breeds of silkworm, Bombyx mori L. International Journal of Agricultural Research, 2 (2): 1-9

Gowda, V., Kalpana, G. V. and Ashwath, S. K. (2013). Evaluation and Identification of Potential Bivoltine Silkworm Hybrids of Bombyx mori L. Journal of Entomology and Zoology Studies, 1 (6): 39-43

Kamili, A. S., Malik, G. N., Trag, A. R., Kukiloo, F. A. and Sofi, M. A. (2000). Development of new bivoltine silkworm Bombyx mori L. genotypes with higher commercial characters. SKUAST Journal of Research, (2):66-69

Krishnaswami, S. (1978). New Technology of silkworm rearing. In: Bulletin No. 2, Central Sericultural Research and Training Institute, Mysore, India, Pp. 23

Lakashmanan, V. and Sureshkumar, N. (2012). Evaluation of new bivoltine silkworm hybrids of Bombyx mori L. for sub-tropical conditions. International Journal of Science and Nature, 3(1): 129-136

Lakshmi, H., Rameshbabu, M., Saha, A. K. Chandrashekharaiah and Bindroo., B. B. (2012). Studies on the season wise evaluation of productive bivoltine silkworm (Bombyx mori L.) hybrids in tropical conditions. International Journal of Integrative sciences, Innovation and Technology, 1(1): 20-30

Malik, G. N., Kamili, A. S., Wani, S. A., Dar, H. U., Ahmad, R. and Sofi, A. M. (2002). Evaluation of some bivoltine silkworm (Bombyx mori L.) genotypes. SKUAST Journal of Research, 4: 83-87

Malik, G. N., Rufaie, S. Z., Baqual, M. F., Kamili, A. S. and Dar, H. U. (2006). Comparative performance of some bivoltine silkworm Bombyx mori L. hybrids. Entomon, 1: 61-64

Malik, M. A., Kamili, A. S., Sofi, A. M., Malik, G. N., Sabahat, A., Bhat, S. A. and Malik, F. A. (2009). Second commercial silk worm rearing in Kashmir- A ray of hope. Indian Silk, 9: 10-11

Malik, M. A., Kamili, A. S., Sofi, A. M., Malik, G. N., Sabahat, A. and Malik, F. A. (2010b). Evaluation and identification of region/season specific bivoltine hybrids of the silkworm Bombyx mori L. Suitable for Kashmir climatic conditions. Journal of Experimental Zoology India, 13: 171-176

Malik, M. A., Sofi, A. M., Malik, G. N., Kamili, A. S. Sabahat, A. and Malik, F. A. $(2010 a)$. Identification of autumn specific breeding resource material of Bombyx mori L. Suitable for second commercial rearing under Kashmir climatic conditions. Journal of Experimental Zoology India, 13: 139-142

Malik, M. A. (2009). Kashmir Sericulture - Its economic potential. International Journal of Agricultural Sciences, 5 (2): 619-623

Malik, M. A., Sabhat, A and Malik, F. A. (2010). Studies on differential adaptation of selected races of the silkworm (Bombyx mori L.) to temperate climates. International Journal of Agricultural Sciences, 6(1) : 48-53

Mandal, K. and Moorthy, S. M. (2016). Evaluation and identification of superior bivoltine silkworm breeds of Bombyx mori L. Annals of Biological Research, 7(2):19-23

Mano, Y., Nirmal Kumar, S., Basavaraja, H. K., Mal Reddy, 
N. and Datta, R. K. (1993). A New method to select promising silkworm breeds/combinations. Indian Silk, 31 (10): 53

Maqbool, A., Dar, H. U., Ahmad, M., Malik, G. N., Zaffar, G., Mir, S. A. and Mir, M. A. (2015). Comparative performance of some bivoltine silkworm (Bombyx mori L.) genotypes during different seasons. Scientific Research and Essays, 10(12): 407-410

Nisar, M., Chisti, M. Z. and Khan, M. A. (2013). Studies on the identification of summer specific silkworm Bombyx mori $\mathrm{L}$. hybrids under temperate climatic conditions of Jammu and Kashmir, India. Journal of International Academic Research for Multidisciplinary, 1 (3): 1-14

Nisar, M., Khan, M.A. and Quadir, S.M. 2005. Evaluation for identification of spring specific silkworm Bombyx mori L. hybrids for commercial exploitation under Kashmir climatic conditions. In: 20th Congress of the International Sericultural Commission, Bangalore, India, 15-18 December, 2005, Vol I, Pp.351-356

Nisar, M., Khan, M. A., Quadir, S. M. and Siddiqui, A. A. 2008. Breeding of Spring Specific Bivoltine Silkworm hybrid SBGP5 X SBGP22. In: Mulberry SericultureProblems and Prospects. APH Publishing Corporation,
New Delhi, India, Pp. 95-104

Nooruldin, S., Bhat, S. A., Malik, M. A., Khan, I. L. and Sahaf, K. A. 2015. Comparative performance of silkworm, Bombyx mori L. hybrids during different seasons under Kashmir climatic conditions. Green Farming, 6 (6): 1392-1395

Qadri, S. F. A., Malik, M. A. Sabhat, A. and Malik, F. A. (2010).Adoption of improved Sericultural practices by Sericulturists in border area of Kashmir. International Journal of Agriculture Statistics and Sciences, 6 (1): 197-201

Senapati, M. D. and Hazarika, A. D. (2014). Evaluation of some productive hybrids of Bombyx mori L. suitable for the autumn seasons in the rainfed condition of Assam, India. The Clarion, 3(2): 43-52

Talebi, E. and Subramanya, G. (2009). Genetic distance and heterosis through evaluation index in the silkworm, Bombyx mori (L.). American Journal of Applied Sciences, 6: 1981-1987

Thiagarajan, V., Bhargava, S. K., Ramesh Babu, M. and Nagaraj, B. (1993). Differences in seasonal performance of twenty six strains of silkworm, Bombyx mori L (Bombycidae). Journal of Lepidopteron Society, 4: 321337 